\title{
SANTA TRIFINA E O REI ARTUR: O TEATRO MEDIEVAL BRETÃO E A COLETA DA LITERATURA ORAL CÉLTICA NA BRETANHA DO SÉCULO XIX
}

\author{
Ana Donnard \\ Universidade Federal de Uberlândia
}

RÉSUMÉ: La tragédie Sainte Trifina et le roi Arthur (Santez Tryphina hag ar Roue Arthur) possiblement reprend une légende hagiographique du répertoire de la littérature orale bretonne de fond médiéval très ancien et la reconfigure dans une pratique théâtrale particulière à la Bretagne rurale du XIX ${ }^{\text {ème }}$. Des agriculteurs et des artisans demi-lettrés se présentaient lors des fêtes populaires avec leurs troupes, fières de jouer du grand théâtre devant les touristes parisiens qui ne voyaient, pourtant, dans ces spectacles, que l'expression du pittoresque et du rudimentaire folklore celtique des paysans. Mais la tragédie en trois jours ne témoigne pas d'une culture populaire inculte, bien au contraire. Létonnant texte, remanié plusieurs fois par la main des curés ou des seigneurs plus au moins lettrés, était mémorisé par les paysans illettrés - eux, bien sûr, habitués à "mémoriser" leur littérature depuis si longtemps. Dans cet article nous essayons de présenter ce contexte entre oralité et tradition écrite à titre d'introduction d'une étude plus approfondie à venir. Sachant qu'il existe très peu d'études sur la littérature celtique et particulièrement bretonne au Brésil, cet article pourra être, nous l'espérons bien, utile.

MOTS-CLÉS: littératures céltiques; théâtre breton; études médiévales.

^anadonnard@ileel.ufu.br 


\section{Resumo da tragédia}

rifina, princesa de Hibérnia (Irlanda), é a esposa de Artur, rei dos Bretões. Seu irmão Kervoura, ajudado pela parteira da rainha, sequestra o filho desta e consegue convencer o rei dos Bretões de que Trifina havia assassinado a criança. $\mathrm{Na}$ verdade, Kervoura havia enviado o bebê à Inglaterra para salvar o rei inglês, que, no seu leito de morte, deveria comer a carne fresca de um recém-nascido, bebendo também o seu sangue. E, para que este "remédio" o curasse, a criança em questão deveria ser fruto de uma união da realeza. A recompensa seria a mão da princesa inglesa para Kervoura, que assim teria o poder sobre as duas Bretanhas - a insular e a continental. Mas o rei Artur, antes de ordenar a execução de Trifina, conclama os Bretões a realizarem um "processo de justiça”, que significava oferecer a chance de defesa à rainha. Seguese, então, um longo périplo de Trifina em busca de provas de sua inocência, mas seu irmão consegue fabricar falsas evidências criando uma armadilha para a santa que, acreditando ir ao encontro de seu irmão Kervoura, é violentada pelos soldados do rei, os quais fazem crer ao soberano que ela, na verdade, teria seduzido o mais novo deles... Trifina é então condenada à decapitação, entretanto, na hora extrema surge seu filho e a livra do suplício. Este filho havia sido salvo pelo bispo de São Malo que, por sua vez, tinha-o capturado das mãos de piratas pagando uma alta quantia. Explica-se, assim, o fato de o rei da Inglaterra ter morrido, pois o bebê que fora oferecido em sacrifício era um substituto encontrado por Kervoura entre camponeses. Liberada pelas mãos de seu filho da decapitação e da desonra, Trifina, santificada pelo sofrimento que lhe fora imposto pelo destino, encontra a felicidade ao lado de seu esposo, de seu filho e do povo que a amará para sempre. Os traidores serão enforcados depois de passarem pelos suplícios da tortura e a Bretanha, liberada de seus traidores, encontrará de novo a ordem e a paz. Os anjos e seus milagres - atores no processo - serão ainda mais adorados pelos Bretões, fiéis devotos cristãos.

\section{Comentário}

O teatro bretão é um grande desconhecido do público internacional. Sabemos muito pouco desta tradição pela via mesma de seus compatriotas. Os estudos em literaturas célticas ainda não constituíram o acervo deste longo percurso de aventura teatral que, como tudo que toca a periferia oeste da Europa, está sujeito a 
controvérsias e discussões intermináveis sobre o valor de uma ou outra versão, sobre os remanejamentos (reescrituras) mais ou menos bemsucedidos ou sobre obras que seriam, supostamente, de falsários. É necessário notar que existiam em 1983 até 250 manuscritos inéditos nas bibliotecas da Bretanha e do País de Gales, segundo Gwennolé Le Menn. ${ }^{1}$ A dificuldade de entendimento entre a cultura erudita e a cultura popular tampouco facilitou o percurso historiográfico deste teatro medieval que, apesar do caráter oral e popular, se pautou também pelas regras da literatura escrita, como veremos mais adiante.

Françoise Morvan, em seu texto de apresentação da tragédia Santa Trifina e o Rei Arthur (edição bilíngue bretão-francês), ${ }^{2}$ relata-nos parte deste conflito entre letrados e iletrados na Bretanha céltica quando Francis-Marie Luzel, folclorista ativo na coleta da literatura bretã, faz vir para o Congresso Céltico de 1867 a troupe de Pluzunet. Segundo a autora, a encenação é vista pelo grupo de filólogos e folcloristas, dentre os quais Gabriel Milin, como um fiasco. Ela designa este grupo como o "clã dos bardos". Podemos entender que a autora se refere ao círculo formador da sociedade bárdica de 1843, chamada de Breuriez-Breizh, que reunia os estudiosos bretonantes (falantes de língua bretã) e tinha por objetivo criar uma renovação no meio acadêmico e intelectual, com a finalidade de recuperar o patrimônio oral ainda por ser coletado. $\mathrm{O}$ grupo compunha-se de François-Marie Luzel, Gabriel Milin, Prosper Proux, Olivier Souvestre, entre outros, tendo como líder ou penn-sturier Hersart de la Villemarqué.

A autora do texto de apresentação da obra e a tradutora desta tragédia nos reporta ainda que somente Henri Martin, historiador vindo de Paris para o Congresso e não entendedor do bretão, chorava emocionado... Prosseguindo, Françoise Morvan afirma que este teatro popular bretão de origem medieval era um produto de "bárbaros" aos olhos dos letrados da ciência erudita romanista.

Anatole Le Braz defenderá anos mais tarde sua tese sobre o teatro céltico na Universidade de Rennes (1905) diante do júri composto por Georges Dottin e Joseph Loth. Naquela época, os estudos literários célticos dividiam-se entre os representativos do saber institucional universitário, tidos como "celtizantes", e aqueles que, fora dos muros

\footnotetext{
${ }^{1}$ Le Menn, G. Histoire du thêâtre populaire breton. XVe-XIXe siècle. Rennes: Institut Culturel de Bretagne/ Skol et Datsum, 1983.

${ }^{2}$ Luzel, F.-M. Sainte Tryphine et le roi Arthur. Textes établis et presentés par Françoise Morvan. Rennes: PUR, 2003.
} 
das academias, clamavam por uma literatura bretã singular e céltica, detentora de memória entre saber letrado e oralidade. Dentro desse contexto de euforia romântica que se havia espalhado pela Europa, tais folcloristas foram designados como "celtomaníacos" - estigma que lhes valeria muitos dissabores nos anos seguintes.

Entre os "celtomaníacos", folcloristas e etnólogos, estavam também os representantes de um neodruidismo romântico que, como as sociedades de folcloristas, pregavam o retorno às fontes druídicas de uma Bretanha esquecida. O grupo dirigido por Hersart de la Villémarqué - o Breuriez-Breizh - dizia-se não-druídico, mas estava ligado de maneira consistente ao grupo neodruídico da Gorseed do País de Gales, fundado em 1838 pelo arquidruida Cawrdaf. No contexto do Bretonismo movimento bretão pela recuperação da cultura céltica da Bretanha e do regionalismo francês, foi fundada a primeira sociedade druídica bretã, logo após a exposição Universal de Paris, em junho de 1900, tendo como primeiro arquidruida Jean Le Fustec e, em seguida, Yves Berthou, poeta, folclorista e visionário cuja obra não deve ser negligenciada. Porém, a recuperação de mitos de um passado envolto em brumas de mistério e a construção de um "mundo druídico" não escapará à crítica irônica e mesmo sarcástica: os neodruidas escritores e poetas foram ridicularizados pelos universitários, o que teve por consequência que, mesmo hoje, a literatura resultante do movimento literário e folclórico que podemos chamar de neodruidismo permaneça à margem. ${ }^{3}$

As controvérsias e as divergências entre aqueles que trabalhavam no terreno da especulação etnológica e historiográfica e aqueles legitimados pelo rigor científico acadêmico fizeram correr muita tinta. Os debates sobre a literatura bretã e sua importância como arquivo de memórias de um passado céltico, ocorridos entre os "bardos druidas" de um lado e os universitários de outro, no contexto do regionalismo bretão, incluindo nesses grupos os eruditos de origem nobre e/ ou clerical, configuraram de maneira decisiva as bases do celtismo - corrente histórico-literária bastante eclética no tocante à sua formação políticoideológica. Esta corrente tinha como base, sobretudo, a revisão da historiografia literária europeia, antecipando as discussões sobre o cânon

\footnotetext{
${ }^{3}$ Sobre o neodruidismo como movimento literário, cf. Donnard, A. As origens do neodruidismo: entre tradição céltica e pós-modernidade. Revista de Estudos da Religião. São Paulo, vol. II, p. 88-108, 2006 - disponível em: < http://www.pucsp.br/rever/ rv2_2006/p_donnard.pdf >, acesso em 10 de outubro de 2010.
} 
na nossa modernidade. Para o celtismo, tratava-se de reconsiderar a importância das literaturas célticas a partir da Alta Idade Média, ou seja, a partir do século VI, data dos primeiros manuscritos em britônico e gaélico. Depois de Ernest Renan, bretão nascido em Tréguier, e sua obra La poésie des races celtiques, o romantismo e o positivismo tornaramse a tela de fundo destes debates, hoje relativizados pelos estudos literários modernizantes. Na França, será a escola do imaginário fundada por Gilbert Durand que, através de suas análises comparatistas, sobretudo no âmbito da mitologia ou dos mitemas internacionais - virá contribuir para uma nova etapa nos estudos célticos. ${ }^{4}$

Francis-Marie Luzel, principal coletor do teatro medieval bretão, será severamente criticado pelos seus compatriotas. Para os eruditos bretões, as representações dos camponeses na Bretanha não passavam de arte rústica desprovida de importância para a constituição de uma literatura bárdica de origem medieval. Para outros, ainda, elas consistiam apenas em encenações ridículas de gente sem instrução. Mas estas representações diante das igrejas na zona rural bretã tinham um público fiel. Ademais, a paixão com a qual homens, mulheres e crianças se consagravam à árdua tarefa de colocar em cena os textos dos manuscritos recopiados de geração em geração são testemunho da importância deste teatro no meio popular. Assim, o teatro medieval bretão, que era ainda representado no século dezenove nas pequenas vilas da região do Trégor e de Vannes, era menosprezado e adorado ao mesmo tempo, numa dinâmica bem conhecida na Bretanha. Tal situação é fruto de uma dicotomia na cultura bretã, que se expressa entre aquilo que rejeita e o que reivindica como autêntico, entre o que considera essas manifestações o resultado de uma erudição legitimada e o que as considera fruto de especulação ou derrapagem ideológica. Isto, no nosso entendimento, é simplesmente uma dinâmica própria das culturas minoritárias célticas, a qual, na Bretanha, traduz-se por uma clivagem entre as histórias bretã e francesa, conduzindo sistematicamente a um recalcamento, num

\footnotetext{
${ }^{4}$ Sobre as circunstâncias ideológicas e políticas do celtismo bretão cf. Le Stum, P. Les origines bardiques du mouvement breton (1900-1914). Mémoire de maitrise, dact. Brest: 1985./ Guyomar, J.-Y. Régionalisme, fédéralisme et minorités nationales en France entre 1919 et 1939. Le Mouvement social. Rennes, n. 70, p. 89-108./ Para uma nova etapa modernizante sobre os estudos célticos cf. Brown, T. (Org.). Celticism. Collection studia imagologica. Amsterdam: Rodopi Éditions, 1996.
} 
primeiro momento, de tudo o que esta cultura não pode explicar facilmente pelas vias de sua história híbrida céltica e francesa. ${ }^{5}$

Anatole Le Braz, em pesquisa citada anteriormente intitulada Le Théâtre Celtique, chegará mesmo a negar categoricamente a existência de uma especificidade bretã, e reduzirá o teatro bretão a uma sucursal do teatro medieval francês. ${ }^{6}$ Se a tese de Le Braz é importante pela documentação e pelo estudo que propõe, sendo ainda uma referência incontornável para estudos sobre o teatro céltico, é preciso que ela seja tomada à luz de uma leitura crítica que dará conta do contexto ideológico entre romanistas e celtizantes no romantismo francês. Hoparz Hemon, linguista, jornalista e poeta bretão, não hesita em condenar a tese de Le Braz inteiramente.

Para se compreender este teatro bretão, é preciso acrescentar à expressão o termo popular - pois se trata de uma característica das literaturas célticas, ou seja, um trânsito singular entre expressão de memória cultural popular e saber erudito, que caminharam lado a lado desde a era medieval até a coleta dos folcloristas românticos e que, ainda hoje, sobrevivem nas formas modernas e pós-modernas de recriação literária e folclórica. Tais riqueza e singularidade são visíveis diante de comparações com o que acontecia no teatro representado no restante da Europa. Dois exemplos: as tragédias Santez Tryphina hag ar Roue Arzur - "em dois dias e oito atos", objeto deste artigo, e Buez Santes Nonn, peça conservada em um manuscrito de aproximadamente 2100 versos. Parece claro que estas tragédias não poderiam ser fruto de um fenômeno isolado de manifestação popular ocasional, mas se inserem numa tradição de origem céltica a merecer estudos em sua dimensão própria de língua e cultura britônica. ${ }^{8}$

\footnotetext{
${ }^{5}$ Estes aspectos não cabem neste trabalho, mas remetemos o leitor aos estudos publicados sobre a identidade bretã no curso das novas teorias em ciências sociais na França: Simon, P.-J. La Bretonnité: une ethnicité problématique. Rennes: PUR/Terre de Brume, 1999./ Le Coadic, R. L'identité bretonne. Rennes: PUR/ Terre de Brume, 1998./ Carrer, P. L'envers du décor. Ethnopsychiatrie en Bretagne et autres terres celtes. Collection Essais. Rennes: Coop Breizh, 1999./ Morvan, F. Le Monde comme si. Nationalisme et dérive identitaire en Bretagne. Rennes: Actes Sud, 2002.

${ }^{6}$ Le Braz, A. Le théatre celtique. Paris: Réédition Robert Laffont (1904), 1997.

${ }^{7}$ Le Duc, G. Le théâtre populaire breton du moyen âge au XIXème. siècle. Bretagne des livres. Rennes, novembre 2001.

${ }^{8}$ A síntese de Gwennolé Le Menn está disponível no mercado e é uma referência obrigatória. Cf. referências ao fim do artigo.
} 
Portanto, a partir de uma primeira abordagem do teatro bretão, somos confrontados com as seguintes evidências: trata-se de uma tradição atestada, revelando as características de um teatro "nacional" ou "regional", como querem os franceses, testemunho de uma sociedade de forte tradição de oralidade que retrabalhou, durante séculos, os temas preferidos, diante de uma audiência rural, semiletrada e singularmente atrelada a seus mitos medievais. Uma fusão entre cultura erudita e cultura popular representa para os estudos literários comparados um dos grandes atrativos da literatura bretã e, no caso de seu teatro, podese ver a continuação de um fundo de memória erudita medieval que, segundo Yves Le Berre, pôde ser salva pela memória popular pelo fato de contar, nas representações realizadas na zona rural, com uma audiência apaixonada. ${ }^{9}$

O teatro popular bretão compreende cinco fases, a saber: os ciclos do Antigo e do Novo Testamento, o ciclo dos Santos, o ciclo romanesco e o teatro cômico. Os mais antigos manuscritos correspondem à fase do médio-bretão, como a Vie de Sainte Nonn, escrita na segunda metade do século dezesseis, sendo o mais importante documento literário para esta fase da língua bretã. ${ }^{10}$ A Vie des trois rois, impresso na cidade de Vannes em 1745, é o único texto teatral impresso na França no século dezoito - o que nos leva a acreditar na importância deste teatro "popular" na Bretanha.

Para os séculos precedentes ao médio-bretão, ou seja, anteriores a 1100, somos obrigados a nos restringir a uma hipotética existência de dramaturgia, na falta de manuscritos sobreviventes. Esta hipótese não tem nada de improvável. León Fléuriot havia assinalado, em seus estudos históricos, um vocabulário do teatro em velho-bretão, ou seja, no estado da língua a partir do século VI, e que atesta uma atividade dramática significativa na Alta Idade Média, portanto. Os exemplos são: uanetou para "histriões", anhuariat para "ator", clesmanctohan para "bufão", jongleur e herderchan ou "aquele que se mostra em cena". Mais significativos ainda são os termos racloriou para "antecena", guan para "cômico" e guarima para "teatro" ou "lugar onde se faz uma encenação", ou seja, "palco". ${ }^{11}$ É bem possível, portanto, que esta tradição de um teatro

\footnotetext{
${ }^{9}$ Le Berre, Y. Lécriture du breton dans l'histoire. Essai de synthèse. Bretagne linguistique. n. 7, p. 153-176, 1991.

${ }^{10}$ O termo "médio-bretão" designa o estado da língua entre 1100 e 1650.

${ }^{11}$ Esta palavra se inscreveu na toponímia da Bretanha: Goariva na Cornualha e no Trégor, Goarivan na região do Leão e Houariva na região de Vannes.
} 
popular medieval em versos seja a continuação de um longo processo de assimilação de mitologia céltica e de doutrina cristã, associada a uma tradição bárdica britônica de origem antiga, representada até o século dezenove por troupes de camponeses pobres e artesãos de uma Bretanha apaixonada pelos seus santos e pelas suas personagens históricas.

As obras escritas em versos são todas em rimas internas, característica de marca da métrica bretã, cuja regra de base é fazer rimar a antipenúltima sílaba de cada verso com a sua própria cesura. ${ }^{12}$ Escolas de poesia certamente existiram, mas o que se pôde recolher como documentação não ofereceu dados consistentes para identificar a estrutura e tampouco o funcionamento destas escolas. O papel dos padres da Igreja bretã foi fundamental ao longo de três séculos de memória, estando o teatro bretão visivelmente relacionado com a vida religiosa de uma sociedade muito devota. Contudo, é claro que tudo isso não impediu os conflitos entre atores e o clero, ou entre o clero bretão e o clero francês. O particularismo da Igreja bretã tinha feito deste teatro um meio de expressão popular característica e trazia para a Bretanha turistas curiosos, espantados por ver em pleno século dezenove encenações de um teatro medieval que havia perdurado na memória das almas simples.

Se podemos identificar claramente o apoio dado pelos padres bretões a estas manifestações teatrais na Bretanha, não podemos, no entanto, esquecer o fato de que a Igreja também exerceu, em contrapartida, sua censura, aliada, é claro, aos poderes seculares controladores da vida destes rústicos camponeses. Uma lei de 17 de novembro de 1548 proibia na França as encenações dos antigos mistérios. Mas, se no resto da França este teatro popular viu-se esquecido, na Bretanha ele persistiu até mesmo contra a interdições locais. Contra a hostilidade da Igreja e suas providências para deter esta onda popular, sobreviverá o teatro bretão, e isso só pode ser entendido a partir de uma história regional/ nacional especificamente bretã e céltica, ou seja, através da expressão literária e artística própria desta cultura. Para a edição da tragédia bretã Santa Trifina e o rei Arthur, o coletor Francis-Marie Luzel pôde adquirir sete manuscritos: três fazem parte do acervo da Biblioteca Municipal de Quimper, e quatro estão na Bibliothèque Nationale de France.

${ }^{12}$ Os manuscritos das peças escritas em versos são todos anteriores a 1650. 


\section{Referências}

BANNIARD, M. Viva Voce. Communication orale et communication écrite du IV au $I X^{e}$ siècle dans l'Occident latin. Paris: Institut des Études Augustiniennes, 1992.

BROWN, T. (Org.). Celticism. Collection studia imagologica. Amsterdam: Rodopi Éditions, 1996.

CARRER, P. L'envers du décor. Ethnopsychiatrie en Bretagne et autres terres celtes. Colection Essais. Rennes: Coop Breizh, 1999.

COHEN, G. Le théâtre en France au Moyen Âge. Paris: PUF, 1948.

de COURSON DE LA VILLENEUVE, A.-M. Histoire des peuples bretons dans la Gaule et dans les îles britanniques. Langue, coutumes, mœurs et institutions. Paris: Furne, 1846. DONNARD, A. As origens do neodruidismo: entre tradição céltica e pósmodernidade. Revista de Estudos da Religião. São Paulo, v. II, p. 88-108, 2006 - disponível em: <http://www.pucsp.br/rever/rv2_2006/p_donnard.pdf>, acesso em $10 \mathrm{de}$ outubro de 2010.

ERNAULT, E. Lancien mystère de Saint Gwenolé. Annales de Bretagne. Rennes, tomeXL-XLI, 1932-1933.

. La Bretagne et les pays celtiques. L'ancien vers breton, exposé sommaire, avec exemples et pièces en vers bretons anciens et modernes. Paris: Honoré-Champion, 1912. 1887.

. La vie de Sainte Nonne. Revue Celtique. t. VIII, p. 230-301/ p. 406-491, Paris:

FLEURIOT, L.; LOZAC'HMEUR,J.-C.; PRAT, L. Récits et poèmes celtiques, domaine brittonique, $V I^{e}-X V^{e}$ siècles. Paris: Stock, 1981.

GUYOMAR, J.-Y. Régionalisme, fédéralisme et minorités nationales en France entre 1919 et 1939. Le Mouvement social. Paris, n. 70, p. 89-108.

GUYONVARC'H, C.; LE ROUX, F. Les druides. Rennes: Éditions Ouest-France, 1986.

LAURENT, D.; TREGUER, M. La nuit celtique. Rennes: PUR/Terre de Brume, 1997. de LA VILLEMARQUÉ, H. Le Barzhaz Breizh. Trésor de la littérature orale de la Bretagne. Spezet: Coop Breizh, 1997.

LAURENT, D. Les passeurs de mémoires. Melleac: Association du Manoir de Kernault, 1996.

LEBÈGUE, R. Le théâtre breton ancien et essais récents. In: Conférences universitaires de Bretagne (1942-1943). Paris: Les Belles Lettres, 1943, p. 39-59.

LE BERRE, Y. L'écriture du breton dans l'histoire. Essai de synthèse. Bretagne linguistique. n. 7, p. 153-176, 1991.

LE BRAZ, A. Le théâtre celtique. Paris: Réédition Robert Laffont (1904), 1997.

LE COADIC, R. L'identité bretonne. Rennes: PUR/ Terre de Brume, 1998.

LE DUC, G. Le théâtre populaire breton du moyen âge au XIXème. siècle. Bretagne des Livres. Rennes, p. 4-6, novembre 2001. 
LE MENN, G. Histoire du théâtre populaire breton. XVe-XIXe siècle. Rennes: Institut Culturel de Bretagne/ Skol et Datsum, 1983.

Bretagne et Pays celtiques, langues, histoire, civilisation, mélanges offertes à la mémoire de Léon Fleuriot. Rennes: Skol/ PUR, 1992.

. Les croyances populaires dans quelques textes bretons $\left(\mathrm{XV}^{\mathrm{e}}-\mathrm{XVII} \mathrm{I}^{\mathrm{e}}\right.$ siècles. In: Religions et mentalités au moyen âge. Mélanges en l'honneur de Hervé Martin. Rennes: PUR, 2003, p. 427-435.

LE ROUX, F. Introduction générale à l'étude de la tradition celtique. Ogam. Rennes, v. XIX, 1967.

LE STUM, P. Les origines bardiques du mouvement breton (1900-1914). Mémoire de maîtrise, dact. Brest: 1985.

LUSIGNAN, S. Oral and written traditions in the Middle Ages. New Literary History. Rennes, v. XVI, n. 1, 1984.

. Journal de route et lettres de mission. Edités par Françoise Morvan, Rennes: Terre de Brume, 1994.

LUZEL, F.-M. Sainte Tryphine et le roi Arthur. Textes établis et presentés par Françoise Morvan. Rennes: PUR, 2003.

MESLIN, M. Le merveilleux, l'imaginaire et les croyances en occident. Paris: Bordas, 1997. MORVAN, F. François-Marie Luzel, enquête sur une expérience de collectage folklorique en Bretagne au XIXe siècle. Rennes: PUR/ Terre de Brume, 1999.

Sud, 2002.

Le Monde comme si. Nationalisme et dérive identitaire en Bretagne. Rennes: Actes

POIRON, D. Le merveilleux dans la littérature française du moyen age. Paris: Presses Universitaires de France, 1982.

POSTIC, F. (Org.). La Bretagne et la littérature orale en Europe. Mellac/ Brest: Centre de Recherche Bretonne et Celtique, 1999.

SEBILLOT, P. Contes populaires de la haute Bretagne. Rennes: Terre de Brume, 1998.

SIMON, P.-J. La Bretonnité: une ethnicité problématique. Rennes: PUR/ Terre de Brume, 1999.

SOUVESTRE, E. Les derniers Bretons. Rennes: Terres de Brume, 1997. 2 vols.

STERCK, C. Débris mythologiques en Basse-Bretagne. In: LE MENN, G. Mélanges offerts à la mémoire de Léon Fleuriot. Bretagne et pays celtiques: langues, histoire, civilisation. Saint-Brieuc: Skol, 1992.

Survivances de la mythologie celtique dans quelques légendes bretonnes. Études Celtiques. v. XXIII, 1985.

STRIWSKI, S. Les Bretons. Essai de psychologie et de caractérologie provinciales. Rennes: Plihon, 1952.

TANGUYB.; GARREAU J.; CASTELY.-P. Bretagne intérieure L'Argoat, terres d'Histoire et de légendes. Toulouse: Privat, 1995.

Recebimento contínuo - Aceite: 15 de maio de 2011 